\title{
Trends in the epidemiology of purple urine bag syndrome: A systematic review
}

\author{
HSIU-WU YANG ${ }^{1,2}$ and YU-JANG SU ${ }^{1-4}$ \\ ${ }^{1}$ Department of Emergency Medicine, Mackay Memorial Hospital, Taipei 10449; ${ }^{2}$ Department of Medicine, \\ Mackay Medical College, New Taipei City 252; ${ }^{3}$ Department of Oral Hygiene, College of Oral Medicine, \\ Taipei Medical University, Taipei 110; ${ }^{4}$ Mackay Junior College of Medicine, \\ Nursing and Management, New Taipei City 25245, Taiwan
}

Received January 1, 2018; Accepted January 23, 2018

DOI: $10.3892 /$ br.2018.1046

\begin{abstract}
Purple urine bag syndrome (PUBS) is rarely observed in clinical practice. The present study aimed to identify the epidemiological trends in PUBS in recent decades. A search of PubMed articles published between 1980 October and 2016 August was conducted, in which 106 articles (174 cases) described PUBS. Of these cases, 58 cases were excluded: 14 cases without mention of gender, 4 cases without description of age, 37 cases without mention of white blood cell (WBC) count, shock status, fever status or description of etiology, and 3 cases without information on mortality. The remaining 116 PUBS cases were collected and analyzed in the present study. The articles were divided into three groups by publication year: 1991 to 2000,2001 to 2010 and 2011 to 2016. The $\chi^{2}$ test was used for statistical analysis, with $\mathrm{P}<0.05$ (two-tailed) defined as the threshold for significance. Of the total enrolled cases, there were 47 men (40.5\%) and 69 women $(59.5 \%)$, with a mean age \pm standard deviation of $75.6 \pm 12.8$ years. Of these, 98 cases $(84.5 \%)$ were elderly $(\geq 65$ years old). A total of $93.1 \%$ of cases had a urine $\mathrm{pH}>7$ while $6.9 \%$ of cases had acidic urine $(\mathrm{pH}<7)$. Furthermore, although WBC count elevated progressively, the mortality rate of patients with PUBS decreased over subsequent decades. This necessitates the advancement of antibiotics and application of early goal-directed therapy. Additionally, the overall mortality rate of PUBS (1980-2016) was 6.8\%, which decreased to $4.3 \%$ in the last 5 years (2011-2016). In conclusion, although PUBS has previously been considered a benign process in the majority of indwelling catheterized patients, emphasis is required on early examination and aggressive antibiotic administration.
\end{abstract}

Correspondence to: Dr Yu-Jang Su, Department of Emergency Medicine, Mackay Memorial Hospital, 92 Section 2 Chung-Shan North Road, Taipei 10449, Taiwan

E-mail: yjsu.5885@mmh.org.tw

Key words: purple urine bag syndrome, elderly, diabetes mellitus, uremia, constipations

\section{Introduction}

Purple urine bag syndrome (PUBS) is an uncommon condition that occurs in urinary catheterized patients with urinary tract infection (UTI). It was first described in 1978, though a possible mechanism was not established until $1988(1,2)$. With regard to the mechanism, tryptophan is metabolized by intestinal bacteria, after which the by-product indoxyl sulfate is expelled into the urine and digested into indoxyl by sulfatases/phosphatases produced by certain bacteria including Escherichia coli (E. coli), Proteus mirabilis, Morganella morganii (M. morganii), Klebsiella pneumoniae, Providencia stuartii, Providencia rettgeri and Pseudomonas aeruginosa $(2,3)$. This indoxyl may convert into indigo and indirubin in the urine drainage bag and create purple discoloration (2).

A higher prevalence of PUBS has been reported in females and in patients with alkaline urine, an indwelling urinary catheter and constipation (3). The majority of patients with PUBS are catheterized due to significant disability, typically being chair-bound or bed-bound elderly patients (3). In previous years, PUBS has been considered to be a benign syndrome rather than a disease with lethal potential, and appropriate empirical oral antibiotics including ciprofloxacin remain to be suggested for its treatment (3). To the best of our knowledge, there have been no previous studies on the clinicopathological or epidemiological trends of PUBS; therefore, the current study retrospectively reviewed PUBS cases for characteristic analysis. A systematic review of PUBS cases reported between October 1980 and August 2016 was conducted, in which data regarding patient age and gender, comorbidities (diabetes mellitus, uremia, constipation and residence in long-term care facility), vital signs (presence or absence of fever), laboratory tests results [seral white blood cell (WBC) count, urine $\mathrm{pH}$ value] and mortality were evaluated. This aimed to identify trends in the epidemiology of PUBS. Through the systematic approach, the different clinicopathological aspects and general trends of PUBS were determined.

\section{Materials and methods}

Search strategy and article selection. A systematic review was designed to investigate clinicopathological characteristics 
in PUBS, including patient age and gender, urine $\mathrm{pH}$ value, presence of fever, shock (defined by hypotension), WBC count, constipation and comorbidities (diabetes mellitus, uremia), urine culture bacteriology, rates of patients in long-term care units and mortality. To determine the trends in the epidemiology of PUBS, the differences in these characteristics over three decades were also analyzed. A search was performed for articles in the PubMed database (https://www.ncbi.nlm.nih. gov/pubmed/) including the word 'purple urine bag syndrome' in the title, published in the period from January 1, 1980 to September 1, 2016. A total 106 relevant articles were identified. Of these, 33 articles were excluded owing to ineligibility or lack of essential information. The full exclusion criteria are depicted in (Fig. 1). Therefore, 71 articles with patient data on 116 cases (4-74) were collected for review (Table I). The articles were divided into three groups by publication year: 1991 to 2000, 2001 to 2010 and 2011 to 2016. The following clinical features were defined as: i) Elderly patients: age $\geq 65$ years old; ii) fever: body temperature $\geq 38^{\circ} \mathrm{C}$; iii) hypotension: systolic blood pressure $<90 \mathrm{mmHg}$ or diastolic blood pressure $<60 \mathrm{mmHg}$.

Statistical analysis. The data was analyzed with SPSS statistical software for Windows, version 11.5 (SPSS Inc., Chicago, IL, USA). Values are presented as the mean \pm standard deviation. Statistical $\chi^{2}$ tests were performed and the threshold for significance was set at $\mathrm{P}<0.05$ (two-tailed).

\section{Results}

Description of the selected articles. In the present study, 106 relevant articles were retrieved. Following application of the inclusion and exclusion criteria, 71 eligible articles (4-74) were selected (57 in English, 4 in French, 3 in Spanish, 3 in Japanese, 1 in Chinese, 1 in German, 1 in Icelandic and 1 in Czech; Fig. 1 and Table I). All the selected articles were images in clinical medicine, individual case reports or serial case reports. The 71 articles included a total of 116 PUBS cases aged from 36 to 100 years old with a mean age \pm standard deviation of $75.6 \pm 12.8$ years. Of these, 47 cases were male (40.5\%) and 69 were female (59.5\%). Of these, 98 cases (84.5\%) were elderly ( $\geq 65$ years old).

Clinical characteristics in PUBS. The mean age of the patients was 75.6 years old, and PUBS was more commonly observed in females than in males (1.5:1 ratio). As PUBS is associated with infectious pathology, mean WBC was determined for the cases, which was elevated to 12,242 cells $/ \mu$ l. Only $11.8 \%$ of cases presented with fever, and $8.6 \%$ of cases with shock. There were $6.9 \%$ of cases with acidic urine $(\mathrm{pH}<7)$, while the remaining cases $(93.1 \%$ ) had urine $\mathrm{pH}>7$. The majority of cases $(69.8 \%$ ) had constipation, and $58.3 \%$ lived in long-term care units. Regarding chronic co-morbidity, $19.2 \%$ of cases had diabetes mellitus and $18.8 \%$ were uremic patients. Overall mortality rate was $6.8 \%$, thus indicating that PUBS may be associated with patients' mortality and not always a benign process.

Clinical characteristics in trend per decade of PUBS cases. Regarding patient age, urine $\mathrm{pH}$ value, the presence of

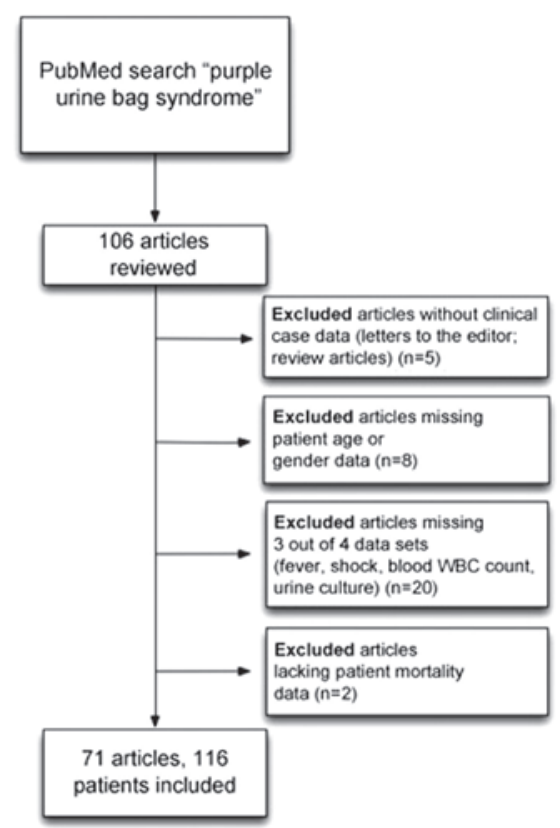

Figure 1. Study inclusion process and enrollment criteria.

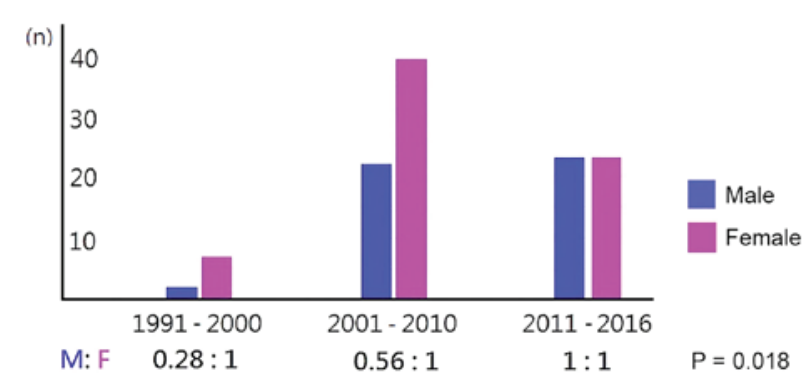

Figure 2. Male to female ratio of purple urine bag syndrome cases per decade.

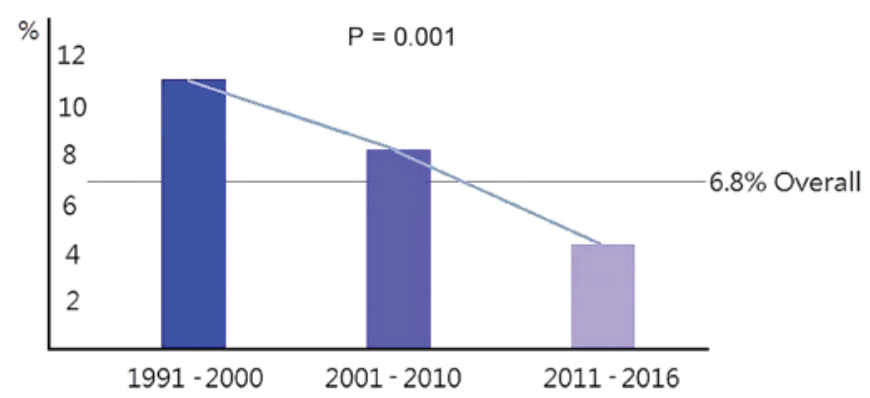

Figure 3. Mortality rate of purple urine bag syndrome cases per decade.

fever, shock or uremia, a history of diabetes, and residence in a long-term care unit, there were no significant changes over subsequent decades among the PUBS cases (Table II). However, an increase in WBC count from 2001-2010 to 2011-2016 ( $\mathrm{P}=0.002$; Table II), and in the male: female ratio with each decade ( $\mathrm{P}=0.018$; Table I and Fig. 2) were identified. Notably, WBC count reached 17,060 14,480 cells $/ \mu 1$ in the most recent five years. Conversely, decreases in constipation rates $(\mathrm{P}=0.011$; Table II) and mortality rates $(\mathrm{P}=0.001$; Table II and Fig. 3) were also identified over the subsequent 
Table I. Case demongraphics of the 71 articles included in the present study.

\begin{tabular}{|c|c|c|c|c|c|c|}
\hline Author & Year & Language & Country & Cases & Mean age \pm SD (years old) & Refs. \\
\hline Umeki & 1993 & Japanese & Japan & 4 & $80 \pm 1.41$ & (4) \\
\hline Nobukuni et al & 1995 & Japanese & Japan & 5 & $60.4 \pm 10.61$ & $(5)$ \\
\hline Al-Jubouri and Vardhan & 2001 & English & UK & 1 & 85 & (6) \\
\hline Ihama and Hokama & 2002 & English & Japan & 1 & 93 & (7) \\
\hline Vallejo-Manzur et al & 2005 & English & USA & 1 & 72 & (9) \\
\hline Wang et al & 2005 & English & Taiwan & $2^{\mathrm{a}}$ & 61 & $(10)$ \\
\hline Rohaut et al & 2005 & French & France & 1 & 81 & $(8)$ \\
\hline Achtergael et al & 2006 & English & Belgium & 1 & 77 & (11) \\
\hline Beunk et al & 2006 & English & UK & 1 & 84 & (12) \\
\hline Tang & 2006 & English & Hong Kong & 2 & $76 \pm 8.49$ & (13) \\
\hline Su et al & 2007 & English & Taiwan & 1 & 61 & (20) \\
\hline Nair et al & 2007 & English & UK & 1 & 83 & (18) \\
\hline Bar-Or et al & 2007 & English & USA & 1 & 68 & (14) \\
\hline Gautam et al & 2007 & English & India & 1 & 70 & $(15)$ \\
\hline Ting et al & 2007 & English & Taiwan & 1 & 72 & (21) \\
\hline Lazimy et al & 2007 & French & France & 1 & 74 & (17) \\
\hline Harun et al & 2007 & English & Brunei & 2 & $60 \pm 21.21$ & (16) \\
\hline Pillai et al & 2007 & English & UK & 1 & 76 & (19) \\
\hline Lin et al & 2008 & English & Taiwan & 10 & $75.3 \pm 2.12$ & (24) \\
\hline Chiang et al & 2008 & Chinese & Taiwan & 1 & 73 & (22) \\
\hline Chung et al & 2008 & English & Taiwan & 1 & 85 & (23) \\
\hline Vidarsdottir et al & 2008 & Icelandic & Iceland & 1 & 72 & (27) \\
\hline Shiao et al & 2008 & English & Taiwan & 14 & $80.9 \pm 11.5$ & (26) \\
\hline Muneoka et al & 2008 & Japanese & Japan & 6 & $87.7 \pm 16.26$ & $(25)$ \\
\hline Tasi et al & 2009 & English & Taiwan & 2 & $64 \pm 19.8$ & $(30)$ \\
\hline Al-Sardar and Haroon & 2009 & English & UK & 1 & 82 & (28) \\
\hline Wu et al & 2009 & English & Taiwan & 1 & 95 & $(32)$ \\
\hline van Iersel and Mattijssen & 2009 & English & Netherlands & 1 & 72 & $(31)$ \\
\hline Pillai et al & 2009 & English & Singapore & 1 & 69 & (29) \\
\hline Ferrara et al & 2010 & English & Italy & 1 & 81 & (33) \\
\hline Hirzallah and D'Souza & 2010 & English & Jordan & 1 & 78 & (34) \\
\hline Siu and Watanabe & 2010 & English & USA & 1 & 48 & $(35)$ \\
\hline Su et al & 2010 & English & Taiwan & 1 & 81 & $(36)$ \\
\hline Kang et al & 2011 & English & Korea & 3 & $74.7 \pm 0$ & (37) \\
\hline Keenan and Thompson & 2011 & English & USA & 1 & 97 & $(38)$ \\
\hline Khan et al & 2011 & English & USA & 1 & 39 & $(39)$ \\
\hline Peters et al & 2011 & English & Australia & 1 & 82 & $(40)$ \\
\hline Zeier et al & 2011 & English & Singapore & 1 & 75 & $(41)$ \\
\hline Bocrie et al & 2012 & English & France & 1 & 87 & $(42)$ \\
\hline Cantaloube et al & 2012 & French & France & 2 & $81.5 \pm 0.71$ & $(43)$ \\
\hline Dominguez Alegria et al & 2012 & Spanish & Spain & 1 & 78 & (44) \\
\hline Meekins et al & 2012 & English & USA & 1 & 67 & $(45)$ \\
\hline Montasir and Mustaque & 2013 & English & Bangladesh & 1 & 86 & $(46)$ \\
\hline Bhattarai et al & 2013 & English & USA & 1 & 87 & $(47)$ \\
\hline Canavese et al & 2013 & English & Italy & 3 & $79 \pm 19.52$ & $(48)$ \\
\hline Duff & 2013 & English & USA & 1 & 57 & $(49)$ \\
\hline Iglesias Barreira et al & 2013 & Spanish & Spain & 2 & $93.5 \pm 2.12$ & $(50)$ \\
\hline Mohamad and Chong & 2013 & English & Brunei & 1 & 78 & $(51)$ \\
\hline Ungprasert et al & 2013 & English & USA & 1 & 44 & $(52)$ \\
\hline Wolff et al & 2013 & French & France & 1 & 90 & $(53)$ \\
\hline Yaqub et al & 2013 & English & Pakistan & 1 & 83 & $(54)$ \\
\hline Agapakis et al & 2014 & English & Greece & 1 & 82 & $(55)$ \\
\hline
\end{tabular}


Table I. Continued.

\begin{tabular}{|c|c|c|c|c|c|c|}
\hline Author & Year & Language & Country & Cases & Mean age \pm SD (years old) & Refs. \\
\hline Chassin-Trubert et al & 2014 & Spanish & Chile & 1 & 72 & (56) \\
\hline Delgado et al & 2014 & English & Mexico & 1 & 60 & (57) \\
\hline Hloch et al & 2014 & Czech & Czech Republic & 1 & 73 & (58) \\
\hline Restuccia and Blasi & 2014 & English & Italy & 1 & 81 & (59) \\
\hline Sheehan & 2014 & English & USA & 1 & 80 & $(60)$ \\
\hline Abubacker et al & 2015 & English & India & 1 & 36 & (61) \\
\hline Alex et al & 2015 & English & India & 1 & 83 & $(62)$ \\
\hline Karim et al & 2015 & English & USA & 1 & 83 & (63) \\
\hline Kenzaka & 2015 & English & Japan & 1 & 72 & (64) \\
\hline Mohamed Faisal et al & 2015 & English & Malaysia & 1 & 68 & $(65)$ \\
\hline Mondragon-Cardona et al & 2015 & English & Colombia & 1 & 71 & (66) \\
\hline Neweling and Janssens & 2015 & German & Germany & 1 & 78 & (67) \\
\hline Redwood et al & 2015 & English & USA & 1 & 90 & (68) \\
\hline Van Keer et al & 2015 & English & Belgium & 2 & $80.5 \pm 0.71$ & (69) \\
\hline Demelo-Rodriguez et al & 2016 & English & Spain & 1 & 83 & (70) \\
\hline Faridi et al & 2016 & English & India & 1 & 76 & (71) \\
\hline Richardson-May & 2016 & English & UK & 1 & 94 & (72) \\
\hline Sriramnaveen et al & 2016 & English & India & 1 & 85 & (73) \\
\hline Tul Llah et al & 2016 & English & USA & 1 & 52 & (74) \\
\hline
\end{tabular}

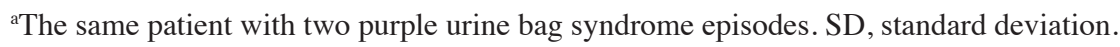

decades. These decreasing rates may be attributed to advancements in antibiotic treatment and the application of early goal-directed-therapy (EGDT).

Bacteriology statistics. Bacterial species identified in urine cultures of the PUBS patients are listed in Table II. Culture results were not available for 9 cases, and there was no bacteria growth for 2 cases. Among the 105 patients with positive results, 3 patients yielded unidentified mixed organisms. The top five most common bacterial species identified were $E$. coli., Enterococcus spp., Proteus spp., M. morganii and Klebsiella spp.

\section{Discussion}

It is well established that urinary tract infection (UTI) may occur at variable ages, while PUBS is commonly observed in elderly compared with non-elderly patients (3), as in the present report $(84.5$ vs. $15.5 \%)$. As we know, PUBS can be observed in sepsis of asymptomatic bacteriuria (ABU) or CA-UTI.

The mechanism of PUBS originates from the dietary digestion and absorption of tryptophan in the bowel. Bacteria in the intestine metabolize the tryptophan to indole, and further hepatic enzymes form the conjugate indoxyl sulfate for secretion into urine by the kidneys. In the urinary tract, gram-negative bacteria phosphatases and sulfatases metabolize the indoxyl sulfate to indoxyl, and through oxidation, this may convert to indigo and indirubin (2). For patients with indwelling catheters, blue indigo deposited on the urine drainage bag surface and red indirubin dissolved in the urine mixes into a purple discoloration (2). A previous study demonstrated that not all bacterial organisms of the same species produce the phosphatase and sulfatase enzymes (2). Based on the above mechanism, bacteriuria should be present in all patients with PUBS, which should be diagnosed as ABU for those without clinical symptoms or signs including fever or shock. A case control study reported that bacterial counts in urine were significantly higher (by 1 to $2 \operatorname{logs}$ ) in patients with PUBS compared with those without the syndrome, thus suggesting that a higher bacterial load in the urine is an important factor leading to PUBS (75).

Regarding gender, females are generally more vulnerable to UTI and PUBS, and female gender has been previously considered a risk factor of catheter-associated (CA)-UTI among urinary catheterized patients $(76,77)$. In the present study, the number of PUBS cases became equal between the genders within the most recent 5 years. A similar finding was observed in a recent prospective observational study performed between November 2011 and October 2013 (78). This study analyzed the incidence of healthcare-associated urinary tract infections in patients admitted to the urology ward of University Hospital 12 de Octubre in Spain with an indwelling urinary catheter. The incidence of CA-UTI in males vs. females was 8.22 vs. $8.46 \%$ without significant difference (78). The study also analyzed the four most frequently cultured bacteria species in CA-UTI (E. coli, Enterococcus, Klebsiella, Pseudomonas) and identified no significant difference between genders. The diversities in the results of these studies results may be affected by other unidentified factors, including urinary catheter management or personal hygiene influence.

In accordance with PUBS being associated with infectious pathology of the urinary tract, the mean WBC count of all reviewed cases was elevated to $12,242 / \mu 1$. Furthermore, WBC 
Table II. Comparisons of purple urine bag syndrome cases $(n=116)$ over the last three decades.

Decade, mean $\pm \mathrm{SD}$ or $\%($ total cases, $\mathrm{n})$

Total period,

mean $\pm \mathrm{SD}$ or $\%$

Decade, mean \pm SD or $\%($ total cases, $\mathrm{n})$

\begin{tabular}{llllll} 
Characteristics & $\begin{array}{c}\text { Total period, } \\
\text { mean } \pm \text { SD or } \% \\
\text { (total cases, } \mathrm{n})\end{array}$ & $1991-2000$ & $2001-2010$ & $2011-2016$ & $\begin{array}{c}\text { P-value } \\
\text { (two-tailed) }\end{array}$ \\
\hline Age & $75.6 \pm 12.8(116)$ & $69.1 \pm 13.1(9)$ & $75.9 \pm 11.3(59)$ & $75.8 \pm 16.8(48)$ & 0.857 \\
Mean WBC count, & $12,242.7 \pm 10,661.5(27)$ & NA & $9,203.3 \pm 3,736.7(15)$ & $17,060.0 \pm 14,480.4(12)$ & 0.002 \\
cells $/ \mu$ l & & & & & \\
Urine pH value & $8.0 \pm 0.9(72)$ & $8.1 \pm 0.7(6)$ & $8.0 \pm 0.9(36)$ & $8.0 \pm 1.1(30)$ & 0.368 \\
Male: female & $47: 69(116)$ & $2: 7(9)$ & $22: 39(61)$ & $23: 23(46)$ & 0.018 \\
Fever & $12.1(14 / 116)$ & $22.2(2 / 9)$ & $9.8(6 / 61)$ & $13.0(6 / 46)$ & 0.360 \\
Shock & $8.6(10 / 116)$ & $0.0(0 / 9)$ & $9.8(6 / 61)$ & $8.7(4 / 46)$ & 0.418 \\
Constipation & $69.8(44 / 63)$ & $100.0(4 / 4)$ & $68.4(26 / 38)$ & $66.7(14 / 21)$ & 0.011 \\
Diabetes mellitus & $19.2(19 / 99)$ & $11.1(1 / 9)$ & $25.6(11 / 43)$ & $14.9(7 / 47)$ & 0.266 \\
Uremia & $18.8(21 / 112)$ & $11.1(1 / 9)$ & $20.0(12 / 60)$ & $18.6(8 / 43)$ & 0.267 \\
Long-term care unit & $58.3(35 / 60)$ & NA & $60.0(27 / 45)$ & $53.3(8 / 15)$ & 0.057 \\
Mortality & $6.8(8 / 116)$ & $11.1(1 / 9)$ & $8.2(5 / 61)$ & $4.3(2 / 46)$ & 0.001 \\
\hline
\end{tabular}

WBC, white blood cell; NA, not available; SD, standard deviation.

count significantly increased with time between 2001-2010 and 2011-2016.

There were $11.8 \%$ of PUBS cases presenting with fever and $8.6 \%$ of cases presenting with hypotension without significant difference between the decades. A total of $58.3 \%$ of subjects lived in long-term care units, and $19.2 \%$ had a history of diabetes. Urine $\mathrm{pH}$ value was the most stationary variable in each decade, varying between 8.0 and 8.1 , which is compatible with the recognized conclusion from studies on PUBS: That PUBS more readily occurs in alkaline over acidic urine (2-4).

A small cohort study of Taiwanese patients demonstrated chronic kidney disease (CKD) to be a risk factor for PUBS (79). The serum and urine levels of indoxyl sulfate are increased markedly in patients with chronic kidney disease or in those undergoing dialysis due to impaired renal clearance (80). In the present study, $18.8 \%$ of PUBS cases had a history of uremia. Previous studies have also indicated comorbid conditions including diabetes mellitus, dementia and iron deficiency anemia are independent risk factors for ABU and UTI $(80,81)$.

It has previously been concluded there is an association of CA-UTI with increased mortality rate and prolonged length of stay in acute care facilities (82). Furthermore, for PUBS involving Fournier's gangrene in immunosuppressed patients, the morbidity and mortality rates were increased (30). Nevertheless, in uremic patients with PUBS, the elimination of indoxyl sulfate during dialysis is limited as it is bound to albumin, leading to exponential increase in serum indoxyl sulfate concentration. When treating patients with CKD and PUBS, clinicians should consider the elevated serum and urinary concentration of indoxyl sulfate due to its potential role in the progression of CKD, as well as its contribution to cardiovascular events (57).

Constipation is considered to be a predisposing factor in PUBS due to the increased time it elicits for bacterial deami-
Table III. Urine culture data of purple urine bag syndrome patients.

\begin{tabular}{lcc}
\hline Bacteria & Cases, $\mathrm{n}$ & $\%$ \\
\hline Escherichia coli & 41 & 23.0 \\
Polymicrobial & 36 & 20.2 \\
Enterococcus spp & 22 & 12.4 \\
Proteus spp & 16 & 9.0 \\
Morganella morganii & 15 & 8.4 \\
Klebsiella spp & 15 & 8.4 \\
Providencia rettgeri & 13 & 7.3 \\
Pseudomonas aeruginosa & 11 & 6.2 \\
Streptococcus spp & 4 & 2.2 \\
Unidentified mixed organisms & 3 & 1.7 \\
Staphylococcus spp & 2 & 1.1 \\
Total & 142 & 100.0 \\
\hline
\end{tabular}

Polymicrobial indicates $\geq 2$ bacterial species.

nation. In the present study, constipation rate significantly decreased after 2001, though this may have been an artifact based on the relatively small number of cases reported in the decade of 1991-2000.

Overall mortality rate was $6.8 \%$, thus indicating that PUBS is not always a benign process. However, mortality rate declined with time over the three decades, concordant with the introduction of EGDT for severe sepsis in 2001 (83). Therefore, this progress may be attributed to the new recommendation of EGDT, which may achieve aggressive correction of septic shock when combined with early appropriate antibi- 
otic administration. Nonetheless, the mortality rate of patients with severe sepsis declined following the implementation of EGDT (84-87). A recent meta-analysis study also concluded that important factors contributing to improved outcome are time-to-first antibiotic administration and appropriate antibiotic use (88).

In conclusion, the ratio of males: females with PUBS increased over recent decades. Therefore, the urine color in catheterized patients should be monitored not only in female but also male patients. PUBS may not always be a benign process, and emphasis is required on early examination and aggressive antibiotic administration. Although WBC count was elevated over the recent decades, the morality rate was lowest in the most recent five years and decreased by decade; the overall mortality rate was $6.8 \%$, and lowered to $4.3 \%$ in the last five years.

This was a case-controlled study that searched relevant articles in the PubMed database. A limitation of this may have been the exclusion of cases based on inadequate information, leading to bias and introducing confounding factors. Furthermore, the relatively small number of PUBS studies in each decade may have limited the accuracy of statistical analyses. There may also be cases of PUBS unreported in the PubMed database which were unaccounted for.

\section{Acknowledgements}

Not applicable.

\section{Funding}

No funding was received.

\section{Availability of data and materials}

The analyzed data sets generated during the study are available from the authors on reasonable request.

\section{Authors' contributions}

The final version of the manuscript has been read and approved by all authors. YHW collected the data and wrote the draft. SYJ planned and revised the study and is the primary correspondent.

\section{Ethics approval and consent to participate}

Not applicable.

\section{Consent for publication}

Not applicable.

\section{Competing interests}

The authors declare that they have no competing interests.

\section{References}

1. Barlow GB and Dickson JAS: PURPLE URINE BAGS. Lancet 311: 220-221, 1978.
2. Dealler SF, Hawkey PM and Millar MR: Enzymatic degradation of urinary indoxyl sulfate by Providencia stuartii and Klebsiella pneumoniae causes the purple urine bag syndrome. J Clin Microbiol 26: 2152-2156, 1988.

3. Su FH, Chung SY, Chen MH, Sheng ML, Chen CH, Chen YJ, Chang WC, Wang LY and Sung KY: Case analysis of purple urine-bag syndrome at a long-term care service in a community hospital. Chang Gung Med J 28: 636-642, 2005.

4. Umeki S: Purple urine bag syndrome (PUBS) associated with strong alkaline urine. Kansenshogaku Zasshi 67: 1172-1177, 1993 (In Japanese)

5. Nobukuni K, Kawahara S, Nagare H and Fujita Y: Study on purple pigmentation in five cases with purple urine bag syndrome. Kansenshogaku Zasshi 69: 1269-1271, 1995 (In Japanese).

6. Al-Jubouri MA and Vardhan MS: A case of purple urine bag syndrome associated with Providencia rettgeri. J Clin Pathol 54: 412, 2001.

7. Ihama Y and Hokama A: Purple urine bag syndrome. Urology 60: 910, 2002.

8. Rohaut B, Bachmeyer C, Lecomte I, Ravet N and Grateau G: A urine bag turns purple. Rev Med Interne 26: 666-667, 2005 (In French).

9. Vallejo-Manzur F, Mireles-Cabodevila E and Varon J: Purple urine bag syndrome. Am J Emerg Med 23: 521-524, 2005.

10. Wang IK, Ho DR, Chang HY, Lin CL and Chuang FR: Purple urine bag syndrome in a hemodialysis patient. Intern Med 44: 859-861, 2005.

11. Achtergael W, Michielsen D, Gorus FK and Gerlo E: Indoxyl sulphate and the purple urine bag syndrome: A case report. Acta Clin Belg 61: 38-41, 2006.

12. Beunk J,Lambert M and Mets T: The purple urine bag syndrome. Age Ageing 35: 542, 2006.

13. Tang MW: Purple urine bag syndrome in geriatric patients. J Am Geriatr Soc 54: 560-561, 2006.

14. Bar-Or D, Rael LT, Bar-Or R, Craun ML, Statz J and Garrett RE: Mass spectrometry analysis of urine and catheter of a patient with purple urinary bag syndrome. Clin Chim Acta 378: 216-218, 2007.

15. Gautam G, Kothari A, Kumar R and Dogra PN: Purple urine bag syndrome: A rare clinical entity in patients with long term indwelling catheters. Int Urol Nephrol 39: 155-156, 2007.

16. Harun NS, Nainar SK and Chong VH: Purple urine bag syndrome: A rare and interesting phenomenon. South Med J 100: 1048-1050, 2007.

17. Lazimy Y, Delotte J, Machiavello JC, Lallement M, Imbenotte M and Bongain A: Purple urine bag syndrome: A case report. Prog Urol 17: 864-865, 2007 (In French).

18. Nair UV, Chattopadhyay I, Giles M, Curtis G and Mannion PT: Purple urine bag syndrome in an octogenarian male. Br J Hosp Med (Lond) 68: 105, 2007.

19. Pillai RN, Clavijo J, Narayanan M, et al: An association of purple urine bag syndrome with intussusception. Urology 70: 812 e1-2, 2007.

20. Su YJ, Lai YC and Chang WH: Purple urine bag syndrome in a dead-on-arrival patient: case report and articles reviews. Am J Emerg Med 25: 861 e5-6, 2007.

21. Ting IW, Wang R, Wu VC, Hsueh PR and Hung KY: Purple urine bag syndrome in a hemodialysis patient. Kidney Int 71: 956, 2007.

22. Chiang HC, Huang MS and Cheng CC: An experience providing home care to a victim of cerebral vascular accident and purple urine bag syndrome. Hu Li Za Zhi 55: 98-104, 2008 (In Chinese).

23. Chung SD, Liao CH and Sun HD: Purple urine bag syndrome with acidic urine. Int J Infect Dis 12: 526-527, 2008.

24. Lin CH, Huang HT, Chien CC, Tzeng DS and Lung FW: Purple urine bag syndrome in nursing homes: Ten elderly case reports and a literature review. Clin Interv Aging 3: 729-734, 2008.

25. Muneoka K, Igawa M, Kurihara N, Kida J, Mikami T, Ishihara I, Uchida J, Shioya K, Uchida S and Hirasawa H: Biochemical and bacteriological investigation of six cases of purple urine bag syndrome (PUBS) in a geriatric ward for dementia. Nippon Ronen Igakkai Zasshi 45: 511-519, 2008 (In Japanese).

26. Shiao CC, Weng CY, Chuang JC, Huang MS and Chen ZY: Purple urine bag syndrome: A community-based study and literature review. Nephrology (Carlton) 13: 554-559, 2008.

27. Vidarsdottir H, Palsson R and Gudbjartsson T: Case of the month; purple urine bag syndrome (PUBS). Laeknabladid 94: 383,385, 2008 (In Icelandic).

28. Al-Sardar H and Haroon D: Purple urinary bag syndrome. Am J Med 122: e1-e2, 2009.

29. Pillai BP, Chong VH and Yong AM: Purple urine bag syndrome. Singapore Med J 50: e193-e194, 2009. 
30. Tasi YM, Huang MS, Yang CJ, Yeh SM and Liu CC: Purple urine bag syndrome, not always a benign process. Am J Emerg Med 27: 895-897, 2009.

31. van Iersel $M$ and Mattijssen V: Purple urine bag syndrome. Neth J Med 67: 340-341, 2009.

32. Wu HH, Yang WC and Lin CC: Purple urine bag syndrome. Am J Med Sci 337: 368, 2009.

33. Ferrara F, D'Angelo G and Costantino G: Monolateral purple urine bag syndrome in bilateral nephrostomy. Postgrad Med J 86 $627,2010$.

34. Hirzallah MI and D'Souza DL: Purple urine bag syndrome in a patient with a nephrostomy tube. N Z Med J 123: 68-70, 2010.

35. Siu G and Watanabe T: Purple urine bag syndrome in rehabilitation. PM R 2: 303-306, 2010.

36. Su HK, Lee FN, Chen BA and Chen CC: Purple urine bag syndrome. Emerg Med J 27: 714, 2010.

37. Kang KH, Jeong KH, Baik SK, Huh WY, Lee TW, Ihm CG, Lee SH and Moon JY: Purple urine bag syndrome: Case report and literature review. Clin Nephrol 75: 557-559, 2011.

38. Keenan CR and Thompson GR III: Purple urine bag syndrome. J Gen Intern Med 26: 1506, 2011.

39. Khan F, Chaudhry MA, Qureshi N and Cowley B: Purple urine bag syndrome: An alarming hue? A brief review of the literature. Int J Nephrol 2011: 419213, 2011

40. Peters P, Merlo J, Beech N, Giles C, Boon B, Parker B, Dancer C, Munckhof W and Teng HS: The purple urine bag syndrome: A visually striking side effect of a highly alkaline urinary tract infection. Can Urol Assoc J 5: 233-234, 2011.

41. Zeier MG, Lee KG and Tan CS: An elderly nursing home resident with unusual urine bag discoloration. NDT Plus 4: 445-446, 2011

42. Bocrie OJ, Bouchoir E, Camus A, Popitean L and Manckoundia P Purple urine bag syndrome in an elderly subject. Braz J Infect Dis 16: 597-598, 2012

43. Cantaloube L, Lebaudy C, Hermabessière S and Rolland $Y$ : Pastel in the urine bag. Geriatr Psychol Neuropsychiatr Vieil 10 5-8, 2012 (In French).

44. Domínguez Alegría AR, Vélez Díaz-Pallares $M$ Moreno Cobo MA, Arrieta Blanco F and Bermejo Vicedo T: Purple urine bag syndrome in elderly woman with nutritional supplements. Nutr Hosp 27: 2130-2132, 2012 (In French).

45. Meekins PE, Ramsay AC and Ramsay MP: Purple urine bag syndrome. West J Emerg Med 13: 499-500, 2012.

46. Al Montasir A and Al Mustaque A: Purple urine bag syndrome. J Family Med Prim Care 2: 104-105, 2013.

47. Bhattarai M, Bin Mukhtar H, Davis TW, Silodia A and Nepal H Purple urine bag syndrome may not be benign: A case report and brief review of the literature. Case Rep Infect Dis 2013: 863853, 2013.

48. Canavese C, Airoldi A, Quaglia M, Barbè MC, Brustia M, Vidali M, Bagnati M, Andreone S, Corrà T, Sciarrabba C, et al: Recognizing purple bag syndrome at first look. J Nephrol 26 : 465-469, 2013

49. Duff ML: Case report: Purple urine bag syndrome. J Emerg Med 44: e335-e336, 2013.

50. Iglesias Barreira R, Albiñana Pérez MS, Rodríguez Penín I and Bilbao Salcedo J: Purple urine bag syndrome in two institutionalised patients. Rev Esp Geriatr Gerontol 48: 45-47, 2013 (In Spanish)

51. Mohamad $\mathrm{Z}$ and Chong VH: Purple urine bag: Think of urinary tract infection. Am J Emerg Med 31: 265 e5-6, 2013.

52. Ungprasert P, Ratanapo S, Cheungpasitporn W, Kue-A-Pai P and Bischof EF Jr: Purple urine bag syndrome. Clin Kidney J 6: 344 2013.

53. Wolff N, Indaburu I, Muller F and Mariescu Depaire N: Purple urine bag syndrom. Prog Urol 23: 538-539, 2013 (In French).

54. Yaqub S, Mohkum S and Mukhtar KN: Purple urine bag syndrome: A case report and review of literature. Indian Nephrol 23: 140-142, 2013

55. Agapakis D, Massa E, Hantzis I, Paschoni E and Satsoglou E: Purple Urine Bag Syndrome: A case report of an alarming phenomenon. Hippokratia 18: 92-94, 2014

56. Chassin-Trubert C AM: Purple urine bag syndrome: Report of one case. Rev Med Chil 142: 1482-1484, 2014 (In Spanish)

57. Delgado G, Martínez-Reséndez M and Camacho-Ortiz A: Purple urine bag syndrome in end-stage chronic kidney disease. J Bras Nefrol 36: 542-544, 2014

58. Hloch $\mathrm{O}$, Gladišová $\mathrm{D}$ and Horáčková M: Purple urine bag syndrome - rare but substantial symptom of urinary infection. Vnitr Lek 60: 512-513, 2014 (In Czech).

59. Restuccia MR and Blasi M: A PUBS Case in a Palliative Care Unit Experience. Case Rep Oncol Med 2014: 169782, 2014
60. Sheehan M: Monolateral purple urine bag syndrome in a patient with bilateral nephrostomy tubes. Urol Nurs 34: 135-138, 2014.

61. Abubacker NR, Jayaraman SM, R K, Sivanesan MK and Mathew R: Purple Urine Bag Syndrome. J Clin Diagn Res 9: OD01-OD02, 2015.

62. Alex R, Manjunath K, Srinivasan R and Basu G: Purple urine bag syndrome: Time for awareness. J Family Med Prim Care 4: 130-131, 2015.

63. Karim A, Abed F and Bachuwa G: A unilateral purple urine bag syndrome in a patient with bilateral nephrostomy tubes. BMJ Case Rep, 2015. 2015. https://doi.org/10.1136/bcr-2015-212913.

64. Kenzaka T: Purple urine bag syndrome in a patient with a urethral balloon catheter and a history of ileal conduit urinary diversion. Korean J Intern Med 30: 420, 2015.

65. Mohamed Faisal AH, Shathiskumar G and Nurul Izah A: Purple urine bag syndrome: Case report from a nursing home resident with a false alarm of urosepsis. Med J Malaysia 70: 265-266, 2015.

66. Mondragón-Cardona A, Jiménez-Canizales CE, AlzateCarvajal V, Bastidas-Rivera F and Sepúlveda-Arias JC: Purple urine bag syndrome in an elderly patient from Colombia. J Infect Dev Ctries 9: 792-795, 2015.

67. Neweling F and Janssens U: Lila Urin bei einem Patienten mit beidseitiger Nephrostomie. Med Klin Intensivmed Notf Med 111: 731-733, 2016 (In German).

68. Redwood R, Medlin J and Pulia M: Elderly Man With Dark Urine. Purple urine bag syndrome. Ann Emerg Med 66: 436, 440, 2015

69. Van Keer J, Detroyer D and Bammens B: Purple Urine Bag Syndrome in Two Elderly Men with Urinary Tract Infection. Case Rep Nephrol 2015: 746981, 2015.

70. Demelo-Rodríguez P, Galán-Carrillo I and Del Toro-Cervera J: Purple urine bag syndrome. Eur J Intern Med 35: e3-e4, 2016.

71. Faridi MS, Rahman MJ, Mibang N, Shantajit $N$ and Somarendra K: Purple Urine Bag Syndrome- An Alarming Situation. J Clin Diagn Res 10: PD05-PD06, 2016.

72. Richardson-May J, Single case of purple urine bag syndrome in an elderly woman with stroke. BMJ Case Rep: Aug 3, 2016. https://doi.org/10.1136/bcr-2016-215465.

73. Sriramnaveen P, Reddy YS, Sridhar A, Kishore CK, Manjusha Y and Sivakumar V: Purple urine bag syndrome in chronic kidney disease. Indian J Nephrol 26: 67-68, 2016.

74. Tul Llah S, Khan S, Dave A, Morrison AJ, Jain S and Hermanns D: A Case of Purple Urine Bag Syndrome in a Spastic Partial Quadriplegic Male. Cureus 8: e552, 2016.

75. Mantani N, Ochiai H, Imanishi N, Kogure T, Terasawa K and Tamura J: A case-control study of purple urine bag syndrome in geriatric wards. J Infect Chemother 9: 53-57, 2003.

76. Vincitorio D, Barbadoro P, Pennacchietti L, Pellegrini I, David S, Ponzio E and Prospero E: Risk factors for catheter-associated urinary tract infection in Italian elderly. Am J Infect Control 42: 898-901, 2014

77. Eckenrode S, Bakullari A, Metersky ML, Wang Y, Pandolfi MM, Galusha D, Jaser L and Eldridge N: The association between age, sex, and hospital-acquired infection rates: Results from the 2009-2011 National Medicare Patient Safety Monitoring System. Infect Control Hosp Epidemiol 35 (Suppl 3): S3-S9, 2014.

78. Jiménez-Alcaide E, Medina-Polo J, García-González L, Arrébola-Pajares A, Guerrero-Ramos F, Pérez-Cadavid S, Sopeña-Sutil R, Benítez-Sala R, Alonso-Isa M, Lara-Isla A, et al: Healthcare-associated urinary tract infections in patients with a urinary catheter: Risk factors, microbiological characteristics and patterns of antibiotic resistance. Arch Esp Urol 68: 541-550, 2015 (In Spanish).

79. Yang CJ, Lu PL, Chen TC, Tasi YM, Lien CT, Chong IW and Huang MS: Chronic kidney disease is a potential risk factor for the development of purple urine bag syndrome. J Am Geriatr Soc 57: 1937-1938, 2009.

80. Jackson SL, Boyko EJ, Scholes D, Abraham L, Gupta K and Fihn SD: Predictors of urinary tract infection after menopause: A prospective study. Am J Med 117: 903-911, 2004.

81. Nicolle LE: Urinary tract infections in the elderly. Clin Geriatr Med 25: 423-436, 2009.

82. Chant C, Smith OM, Marshall JC and Friedrich JO: Relationship of catheter-associated urinary tract infection to mortality and length of stay in critically ill patients: A systematic review and meta-analysis of observational studies. Crit Care Med 39: $1167-1173,2011$.

83. Rivers E, Nguyen B, Havstad S, Ressler J, Muzzin A, Knoblich B, Peterson E and Tomlanovich M; Early Goal-Directed Therapy Collaborative Group: Early goal-directed therapy in the treatment of severe sepsis and septic shock. N Engl J Med 345: 1368-1377, 2001. 
84. Liu B, Ding X and Yang J: Effect of early goal directed therapy in the treatment of severe sepsis and/or septic shock. Curr Med Res Opin 32: 1773-1782, 2016

85. Xing L, Tong L, Jun L, Xinjing G and Lei X: Effect of early goal-directed therapy on mortality in patients with severe sepsis or septic shock: A Meta analysis. Zhonghua Wei Zhong Bing Ji Jiu Yi Xue 27: 735-738, 2015 (In Chinese).

86. Cai G, Tong H, Hao X, Hu C, Yan M, Chen J and Yan J: The effects of early goal-directed therapy on mortality rate in patients with severe sepsis and septic shock: A systematic literature review and Meta-analysis. Zhonghua Wei Zhong Bing Ji Jiu Yi Xue 27: 439-442, 2015 (In Chinese).
87. Puskarich MA, Marchick MR, Kline JA, Steuerwald MT and Jones AE: One year mortality of patients treated with an emergency department based early goal directed therapy protocol for severe sepsis and septic shock: A before and after study. Crit Care 13: R167, 2009.

88. Kalil AC and Kellum JA: Is Early Goal-Directed Therapy Harmful to Patients With Sepsis and High Disease Severity? Crit Care Med 45: 1265-1267, 2017.

(i)(3) This work is licensed under a Creative Commons Attribution-NonCommercial-NoDerivatives 4.0 International (CC BY-NC-ND 4.0) License. 